\title{
Las miradas cruzadas en la ópera. Reflexiones sobre cuerpo e identidad en Bogotá en el siglo XIX
}

\author{
Exchanging Glances at the Opera. \\ Reflections on Groups and Identity in Bogota \\ during the Nineteenth Century
}

La definición de una identidad por parte de la élite letrada de Bogotá durante el siglo XIX produjo un discurso en torno a lo civilizado. En este texto, proponemos indagar cuáles fueron los mecanismos para observar y controlar los comportamientos civilizados durante una función de ópera. Los cuerpos que se observaban eran cuerpos que, por medio de diferentes estrategias, manifestaban una identidad individual y colectiva. Las miradas cruzadas entre ellos nos permiten definir mecanismos de control y de verificación de una identidad republicana, asociada al ideal de civilización de la nueva república. La mirada del espectador-cronista era diferente según si se dirigía al proscenio, al público femenino o a los otros hombres. Esta mirada quedó consignada en las reseñas, verdaderas crónicas de una élite, cuya lectura oscila entre lo verídico y lo ideado. De esta manera, la ópera aparece como un gran teatro social, ajeno a consideraciones estéticas o artísticas.

Palabras claves: ópera, música colombiana, civilización, identidad, recepción, música y sociedad.

The definition of an identity on the part of the cultural elite of Bogota during the nineteenth century generated a discourse on the subject of the "civilised". This text sets out to explore what the mechanisms for observing and controlling civilised behaviour were during opera performances. The groups that were observed were groups that, by means of different strategies, demonstrated an individual and collective identity. The glances they exchanged enables mechanisms of control to be defined and a Republican identity, associated with the ideal of the civilisation of the new Republic to be verified. The spectator-reviewer's gaze was different in accordance with whether it was directed towards the proscenium, the female public or other men. This view was recorded in the reviews, true chronicles of an elite, whose interpretation oscillated between the truth and the imagined. Opera was therefore seen as a vast social theatre, oblivious to aesthetic or artistic considerations.

Keywords: opera, Colombian music, civilization, identity, reception, music and society. 
En el presente siglo cualquiera sociedad por pobre que sea, con tal que pretenda no más vivir la vida de la civilización, mantiene como una de sus más apremiantes necesidades morales un espectáculo tal como la ópera o el teatro dramático. ¿Qué sociedad es, pues, la de esta ciudad en la que, a vuelta de un retraimiento casi selvático y de una monotonía conventual, no puede aclimatarse y mantenerse tal cual un placer tan honesto, tan grato, tan civilizador como el de la ópera?¹.

Si pudiéramos nombrar alguna apremiante necesidad para el colombiano del siglo XIX, esta sería considerarse civilizado. La ópera se asocia en el imaginario decimonónico a una práctica musical y social definitoria de lo civilizado. Tomando como punto de partida esta cita, queremos mostrar cómo la ópera ofreció un marco para la regulación de una identidad, dentro del contexto de construcción del estado nacional del siglo XIX. Consta nuestro acervo de documentos publicados durante los dos decenios del Olimpo Radical (1863-1886), período caracterizado por un gobierno liberal y federal, antes del viraje conservador de 1886 con la llamada Regeneración de Rafael Núñez y sus consecuencias sobre discursos de socialización, religión, censura, etc. ${ }^{2}$.

Durante el siglo XIX, músicos y aficionados intentaron institucionalizar conciertos públicos, en un esfuerzo por sacar la música del ámbito privado de los salones. La Sociedad Filarmónica, la Unión Musical, el Sexteto de la Harmonía o la Sociedad de Santa Cecilia son algunos de esos proyectos filantrópicos que, cercenados por vicisitudes económicas y políticas, solo darían sus frutos ya entrado el siglo $\mathrm{XX}^{3}$.

La burguesía se apropió de la música europea como un elemento de distinción y fueron apareciendo espacios públicos para el consumo de esta música: el teatro, el casino, la iglesia, los colegios o los parques. A mediados del siglo, con la llegada de la ópera, la escena musical se centró definitivamente en el Coliseo:

Los conciertos musicales que antes eran tan frecuentes, con ocasión de conmemorar una fecha, auxiliar una desgracia o bien como trabajo de artistas distinguidos, han desaparecido casi de nuestras costumbres sociales; y si se exceptúa la ópera [...] todos nuestros espectáculos quedan reducidos a las procesiones religiosas.

\footnotetext{
1 "Teatro Lírico", La Opinión, 25-1-1865, p. 26.

${ }^{2}$ Para este trabajo, las fuentes son en su mayoría publicaciones periódicas del siglo XIX conservadas en las colecciones (del Banco de la República de la Biblioteca Luis Ángel Arango de Bogotá), la Biblioteca Nacional de Colombia y la Hemeroteca de la Universidad de Antioquia en Medellín.

${ }^{3}$ Ellie Anne Duque: "La sociedad filarmónica o la vida musical en Bogotá hacia mediados del siglo XIX", Ensayos: Historia y teoria del arte, 3, 1996, pp. 75-92.

${ }^{4}$ A.C.: "Espectáculos civilizadores", La Opinión, 5-7-1865, p. 211.
} 
El Coliseo Ramírez, inaugurado en 1793, rebautizado Coliseo Maldonado en 1840, expropiado y demolido por el gobierno en 1884, fue el núcleo de la vida teatral y musical en Bogotá y un espacio clave de sociabilidad5.

La música, aquella que congrega el público en esos espacios elegantes, es por antonomasia europea: es la música tonal, de la dirección y la culminación; es la música que va acorde a un tiempo valioso y lineal; que anula un sentido cíclico del tiempo. La música tonal -y su experiencia estésica- mostraba propiedades similares a las del cuerpo moderno: movimiento y quietud, tensión y distensión, preparación, fulminación, excitación, cambios repentinos... redención ${ }^{6}$. Esta nueva "ensonización" permitió valorizar nuevos constructos de audibilidad y escucha -el gusto- al tiempo que el país se orientó hacia un pensamiento más liberal. De esta manera lo sónico y su experiencia quedó atado a la definición de un nuevo orden ${ }^{8}$. Un examen público de piano y canto, por ejemplo, era "una de las verdaderas fiestas de la civilización", al igual que una función de ópera o un concierto.

Así como la nación latinoamericana del siglo XIX puede asimilarse a un constructo en permanente cambio ${ }^{10}$, vamos a observar cómo el cuerpo del sujeto nacional se percibió, se pensó a sí mismo, se transformó y se presentó ante los demás. La ópera fue una gran vitrina social: se expuso una identidad civilizada, subjetiva y colectiva.

Los términos "civilizado, moderno, progreso, bárbaro, salvaje..." abundan en los escritos decimonónicos; su uso refleja las percepciones de un pequeño conjunto de individuos que tienen como norte las naciones europeas posteriores a 1848, cristianas, industriales y republicanas. El historiador Frédéric Martínez nos invita a matizar la noción de "civilización" y "barbarie": para el conservador, era "civilizado" aquello que se alineaba con los principios

${ }^{5}$ Rondy Torres López: Le rêve lyrique en Colombie au XIXe siècle. Prémisses, oeuvres et devenir, tesis doctoral, Universidad París IV-La Sorbona, 2009, pp. 68-72.

${ }^{6}$ John Shepherd, Peter Wicke: Music and Cultural Theory, Cambridge, Polity Press, 1997, pp. 12 y 131. Los autores citan los trabajos de Leonard Meyer, Suzanne Langer y Viktor Zuckerkandl.

7 "As there was an Enlightenment, so too was there an 'Ensoniment': a series of conjunctures among ideas, institutions, and practices rendered the word audible in new ways and valorized new constructs of hearing and listening". Jonathan Sterne: The Audible Past: Cultural Origins of Sound Reproduction, Durham, Duke University Press, 2003, p. 2.

${ }^{8}$ Véase Ana María Ochoa: Aurality: Listening and Knowledge in Nineteenth-Century Colombia, Durham, Duke University Press, 2014, así como Ronald Radano, Tejumola Olaniyan (eds.): Audible Empire: Music, Global Politics, Critique, Durham, Duke University Press, 2016.

9 "Colegio de las Mercedes", La Paz, 15-12-1868. El artículo hace referencia a los exámenes de final de año del Colegio de las Mercedes en 1868, en el que hubo, además de música, pruebas de religión, gramática castellana, aritmética y geografía universal.

${ }^{10}$ La nación "llegó a ser [...] modelada, adaptada y transformada". Benedict Anderson: Comunidades imaginadas. Reflexiones sobre el origen y la difusión del nacionalismo, Eduardo L. Suárez (trad.), México, FCE, 2013, p. 200 (1. . ed. en inglés, 1983). 
tradicionales de una sociedad católica y jerárquica; el liberal entendía por civilizado todo lo referente a la modernidad democrática, siendo "bárbara" la intervención del clero en lo político ${ }^{11}$.

Para este estudio, queremos entender la civilización como una abstracción que se experimentaba y se medía en términos de opuestos en una escala del progreso: más negro/más blanco; más solitario/más poblado; desnudo/cubierto; ignorante/instruido, etc. La definición de civilización por la Real Academia durante el siglo XIX -"'grado de cultura que adquieren pueblos o personas, cuando de la rudeza natural pasan al primor, elegancia y dulzura de voces, usos y costumbres propias de gente culta"12 - hace énfasis en la idea de gradación, al tiempo que explica la experiencia de ser civilizado como el resultado de un recorrido entre un estado natural y una construcción subjetiva en torno a costumbres y comportamientos ${ }^{13}$.

También queremos entender el ser civilizado como un programa impuesto. En la América decimonónica, el proceso civilizatorio dejó de ser una transformación sin plan previo para convertirse en un programa racional, en un "campo de maniobras para las intervenciones planificadas en la red de interrelaciones y en las costumbres psíquicas", como propone el sociólogo Norbert Elias ${ }^{14}$.

Este nuevo camino, asociado a comportamientos y sensibilidades particulares, buscó una antítesis decisiva para expresar su autoconciencia como élite y crear la "condición que [los gobernantes y letrados] esperaban que tuviera el país" ". La sociabilidad, la politesse, la comida, los hábitos en relación con procesos fisiológicos se demarcaron de comportamientos "bárbaros", término que hay que entender con todos los matices de la época. El resultado de este proceso debía ser, a nivel individual, un cuerpo perfectible que incorporase e hiciese visible un capital social y cultural por medio del autocontrol de los impulsos y las emociones. Esta estricta regulación del comportamiento se convertía a su vez en instrumento de prestigio y medio de dominación ${ }^{16}$.

\footnotetext{
${ }^{11}$ Frédéric Martínez: El nacionalismo cosmopolita. La referencia europea en la construcción nacional en Colombia, 1845-1900, Bogotá, Banco de la República-IFEA, 2001, p. 31.

12 Definición de "civilización" desde la edición de 1822 del Diccionario de la lengua castellana por la Real Academia Española (la edición de 1884 se puede consultar en este enlace https://archive.org/details/ diccionariodel00acaduoft).

${ }^{13}$ Culto: dotado de las calidades que provienen de la cultura (Diccionario de la lengua castellana, 12. ${ }^{a}$ ed., 1884).

${ }^{14}$ Norbert Elias: El proceso de la civilización. Investigaciones sociogenéticas y psicogenéticas, Ramón García Cotarelo (trad.), México, FCE, 2016, p. 538 (1. ${ }^{a}$ ed. en francés, 1977).

${ }^{15}$ Zandra Pedraza: En cuerpo y alma. Visiones del progreso y de la modernidad: educación, cuerpo y orden social en Colombia (1830-1990), Bogotá, Uniandes, 2011, pp. 28 y 29. Véase igualmente N. Elias: El proceso civilizatorio..., p. 130.

${ }^{16}$ N. Elias: El proceso civilizatorio..., p. 613.
} 
La élite, otro término que usaremos, era el grupo de familias dueñas de la tierra y del monopolio económico. Por medio de su comportamientos, de su incuestionable mediación con lo civilizado y la permanente referencia a Europa como un arma retórica contra las instituciones del pasado ${ }^{17}$, definía una autoconsciencia que la diferenciaba de otro tipo de poblaciones. La élite se valía de sus orígenes sociales y regionales, su tendencia política, su experiencia militar y sus cargos oficiales, así como de sus apellidos, para mostrar su notoriedad. Se movía en escenarios propios como los salones, los clubes o el teatro, al tiempo que definía la hoja de ruta del saber (universidades, academias, colegios, publicaciones de periódicos y de libros) ${ }^{18}$.

Para escribir este texto, imaginaremos ser un aficionado que asiste a una función de ópera. Su tránsito hacia el teatro y dentro del teatro, lo que observa y lo que consigna en la reseña es la materia para este estudio. Iniciamos con una reflexión sobre la identidad del neogranadino y su engranaje con lo civilizado. En un segundo punto, miraremos el recinto de la ópera como un espacio cerrado propicio para la confirmación de dicha identidad. El vaivén de miradas durante una función de ópera constituye la sustancia de nuestro tercer punto de análisis, miradas que verifican, corrigen y castigan el comportamiento de los asistentes, por ende, su grado de civilización. Nos detendremos sobre la mirada del hombre hacia la mujer o hacia sus congéneres, de los cantantes hacia su público o de las señoritas hacia el proscenio, miradas que permiten lecturas relacionadas con erotismo, eugenesia, burla, censura o educación. Esto nos lleva, como punto final, a cuestionarnos sobre la sinceridad de estos relatos: la reseña es la crónica que conserva la memoria de un pequeño conjunto de personas; como relato de la élite, la reseña exalta y silencia. Sin tibieza ni moderación, estos textos pueden ser matizados con burlas o sátiras que señalan los límites del actuar civilizado en el teatro lírico.

\section{Definir al neogranadino}

La relación entre escritura y poder es un tópico en los actuales estudios latinoamericanistas sobre el siglo XIX ${ }^{19}$. La ciudad letrada o la república de las letras forman parte del vocabulario académico que estudia la nueva configuración neocolonial que invirtió los centros de control. La élite bogotana buscó

\footnotetext{
${ }^{17}$ F. Martínez: El nacionalismo cosmopolita..., pp. 40 y 69.

${ }^{18}$ Juan Camilo Escobar Villegas: Progresar y civilizar. Imaginarios de identidad y élites intelectuales de Antioquia en Euroamérica, 1830-1920, Medellín, Fondo Editorial Universidad EAFIT, 2009, pp. 29 y 34.

${ }^{19}$ Sobre este tema, la producción bibliográfica es numerosa. Véase, entre otros muchos, Ángel Rama: La ciudad letrada, Santiago de Chile, Tajamar, 1996; y en el caso colombiano, el libro de Malcom Deas: Del poder y la gramática y otros ensayos sobre historia, política y literatura colombiana, Bogotá, Taurus, 2006. Más recientemente, Ana María Ochoa se aproxima a dicho tema desde una perspectiva que combina los estudios de sonidos y la mirada decolonial. Ana María Ochoa: Aurality. Listening and Knowledge in Nineteenth-Century Colombia, Durham, Duke University Press, 2014.
} 
autodefinirse por medio de una contradictoria red de vínculos: su identificación parental (europea), su diferencia y autonomía (su neogranadismo), al tiempo que negaba dos otredades: la ibérica y la autóctona ${ }^{20}$.

Nineteenth-century Latin America consisted of at least two immediate tiers of otherness. First, we see the nation-building liberals attempting to embody otherness by freeing themselves from the discourse of Iberian power. [...] The liberals seek a genetic code erased all of traces of autochthony. Herein we have the second tier of otherness: exclusion and even elimination of the internal other -the barbarian- vis-à-vis warcraft, which amounts to statecraft ${ }^{21}$.

El tándem civilización-barbarie estructuró el relato político, social, literario y visual decimonónico; definió un eje fundacional en el que cada cual intentaba situarse. Lo civilizado, asociado a una serie de comportamientos comprometidos en la sociabilidad y la vida privada, tenía que ser visible en un cuerpo, el cuerpo civilizado, objeto de nuestro estudio. Labrado por una disciplina y una presión social, su afectación mostraba lo lejos que había quedado el cuerpo natural, salvaje, entendido como vulgar ${ }^{22}$.

Definir el nuevo sujeto nacional, la "nueva raza republicana" fue un tema en ciernes en el siglo XIX. La Comisión Corográfica, un ambicioso proyecto que recorrió el territorio nacional entre 1850 y 1862 con el objetivo de describir las diferentes costumbres y regiones, planteó varias tecnologías para visualizar la nación: la geografia, la cartografia, la historia, la literatura costumbrista y las acuarelas. Los márgenes de la nación se definieron, confundidos con aquellos de la civilización, ahí donde había extensas llanuras, "desiertos solitarios", paradójicamente habitados por indios o africanos ${ }^{23}$.

La nueva raza republicana, "blanca, inteligente y trabajadora" 24 , concentrada en las ciudades y regiones montañosas, tendría que absorber los diferentes tipos poblacionales, reteniendo las mejores cualidades. Este mestizaje aparece como un discurso oficial que rechaza las formas coloniales de opresión racial pero que se convierte en una ideología inclusiva de exclusión -"an all-inclusive ideology of exclusion"- para retomar el término acuñado por Ronald Stutzman ${ }^{25}$.

\footnotetext{
${ }^{20}$ Esta compleja búsqueda de una identidad define una "subcultura", noción introducida en 1955 por el sociólogo Albert Cohen en su libro Delinquent Boys: The Culture of the Gang, Glencoe, Free Press, 1955.

${ }^{21}$ Aarti Smith Madan: Lines of Geography in Latin American Narrative. National Territory, National Literature, Nueva York, Palgrave Macmillan, 2017, p. 12.

22 Z. Pedraza: En cuerpo y alma..., p. 109.

${ }^{23}$ Nancy Appelbaum: Mapping the Country of Regions. The Chorographic Commission of NineteenthCentury Colombia, Chapel Hill, The University of North Carolina Press, 2016, p. 132.

${ }^{24}$ N. Appelbaum: Mapping the Country..., p. 55.

${ }^{25}$ Peter Wade: "Rethinking Mestizaje: Ideology and Lived Experience", Journal of Latin American Studies, 37, 2005, pp. 241-242. El autor propone una discusión sobre la noción de mestizaje en América Latina, entendido como proceso de integración nacional que enmascara procesos de exclusión racial, tomando como referencia los trabajos de Ronald Stutzman: "El Mestizaje: an All-Inclusive Ideology of Exclusion", Cultural Transformations
} 
El blanqueamiento racial se consideró como la vía de regeneración hacia un nuevo hombre, sustentado por teorías eugenésicas y demográficas ${ }^{26}$. A nivel continental, apareció la idea de "promover intensamente la inmigración desde el norte de Europa para blanquear (whiten) y mejorar el linaje racial" 27 . Incluso se sueña con europeizar los paisajes montañosos de los Andes colombianos: "me ponía a cavilar lo que serían, con el andar del tiempo y con la paz, una vez que penetre en ellos el elemento europeo con los pasmosos adelantos del presente siglo" 28 .

Las instituciones apoyaron todo emprendimiento cultural procedente de Europa. La siguiente cita muestra el entusiasta compromiso de la iglesia con la temporada de ópera, sorprendente en un contexto de censura y prohibición hacia el teatro (que analizaremos más adelante).

Si al cristianismo se deben los dogmas y máximas sublimes que [...] han morigerado el corazón humano, a la música se debe igualmente el refinamiento de este mismo órgano, la dulzura de sus sentimientos, y esa propensiva o nerviosa impresionalidad [sic] que hacen del ser material un ser espiritual, del salvaje un civilizado, del criminal un santo ${ }^{29}$.

A menos que razones económicas justifiquen estas afirmaciones, en 1865, la cantanteVisoni anunció que cedería una cuarta parte de su beneficio a favor de los pobres de San Vicente de Paul. Un columnista, con la acostumbrada chispa santafereña, invita a las religiosas a ocupar... "los palcos santificados" 30 .

Con todo lo anterior, se dibuja la hoja de ruta racial y cultural de una élite republicana, que además de comportamientos y aspiraciones europeas, tenía sus hábitos, sus horarios y sus espacios. Bien emplear el tiempo era uno de los fundamentos para una vida disciplinada y virtuosa, frente al ocio y la pereza ${ }^{31}$.

La ópera, así como los demás espectáculos o fiestas religiosas y patrias, marcaban una ruptura en estas rutinas. Los bogotanos transfirieron al recinto del teatro las características del espacio doméstico, una fortaleza que protegía la identidad

and Ethnicity in Moderne Ecuador, Norman E. Whitten (ed.), Urbana, 1981; y de Florencia Mallon: "Constructing Mestizaje in Latin America: Authenticity, Marginality and Gender in the Claiming of Ethnic Identities", Journal of Latin American Anthropology, 2, 1, 1996, pp. 170-181.

${ }^{26}$ Santiago Castro-Gómez: La Hybris del Punto-Cero. Ciencia, raza e ilustración en la Nueva Granada (1750-1816), Bogotá, Editorial Pontificia Universidad Javeriana, 2005, pp. 38-42.

${ }^{27}$ Shaw William Miller: An Environmental History of Latin America, Cambridge, Cambridge University Press, 2007, p. 107. Para ampliar este tema, véase también A. S. Madan: Lines of Geography... (especialmente el capítulo 3) y para el caso colombiano, N. Appelbaum: Mapping the Country..., p. 110 y J. Arias Vanegas: Nación y diferencia en el siglo XIX colombiano. Orden nacional, racialismo y taxonomías poblacionales, Bogotá, Uniandes-Ceso, 2005, pp. 50 y 120.

${ }^{28}$ J. F. Ortiz: Reminiscencias, Bogotá, Librería americana, 1914, p. 238 (citado por F. Martínez: El nacionalismo cosmopolita..., p. 148).

29 "Los líricos i la ópera de don Pascual", La Opinión, 26-4-1865, p. 135.

30 "La señora de Visoni", La Opinión, 27-9-1865, p. 307.

${ }^{31}$ Germán Mejía Pavony: Los años del cambio. Historia urbana de Bogotá. 1810-1910, Bogotá, CEJA, 2000, pp. 465-477. El autor presenta un análisis del uso del tiempo de hombres y mujeres a mediados del siglo XIX en Bogotá, en el que asocia los ritmos diarios y anuales del uso del tiempo con el fortalecimiento de la virtud. 
de élite de asaltos simbólicos ${ }^{32}$. Los palcos abrieron un ambiguo espacio en donde lo doméstico se prolongaba en lo público.Y dentro de esta nueva arquitectura, se negoció y confirmó la nueva identidad neogranadina; esa apremiante necesidad... de parecer civilizado.

\section{El aseo en el teatro}

En sus recuerdos de viaje a la Nueva Granada, el viajero francés Auguste Le Moyne describió el Coliseo de 1830 como un teatro sencillo, no más grande que Les Variétés de París, sin ornato ni sillas, con una iluminación detestable ${ }^{33}$. Aunque el coliseo nunca se caracterizó por su comodidad, la prensa registró cuidadosamente la lista de mejoras que cada compañía aportó. Perfeccionar el espacio era mejorar la calidad del espectáculo. Quien cruzara el umbral del santuario de Apolo olvidaba una "ciudad en lamentable estado de desaseo; [con] calles sucias, desempedradas a trechos, llenas de fangales y por la noche oscuras como boca de lobo" 34 . Se consolidó entonces un discurso que asoció limpieza con decencia:

El escenario era una miseria: [la compañía] lo ha mejorado con nuevas y muy buenas decoraciones. El interior del teatro, galerías y salón, estaba lamentablemente descuidado y sucio: ella ha hecho desaparecer ese abandono, reemplazándolo con la decencia y la limpieza. [...] Por último, salvo el cigarro, o sea la mala educación del público del salón, todo ha cambiado en nuestro teatro, en el sentido del progreso, de la cultura y del mejor servicio del arte ${ }^{35}$.

Al igual que el lenguaje, lo edificado tiene el poder de definir y refinar la sensibilidad por medio de la interacción con los cuerpos, de dar forma y ensanchar la percepción de las $\operatorname{cosas}^{36}$. Al igual que la urbanidad, el aseo y la higiene pueden modificar la condición del ser humano en miras del progreso. La limpieza, y su relación con cualidades intelectuales y morales, empezó entonces a ser escala de gradación social ${ }^{37}$. Lo sucio, lo repulsivo y lo vulgar podía ser enmendado por la higiene: el nuevo sujeto nacional empezó a percibir tanto su cuerpo como su entorno directo como perfectible ${ }^{38}$

\footnotetext{
${ }^{32}$ G. Mejía Pavony: Los años del cambio..., p. 153.

${ }^{33}$ Auguste Le Moyne: Voyages et séjours dans l'Amérique du Sud. La Nouvelle-Grenade, Santiago de Cuba, la Jamaïque et l'isthme de Panama, París, Quantin, 1880, p. 195.

${ }^{34}$ [Sin título], El Iris, 15-4-1866, p. 106.

35 A.C.: "Espectáculos civilizadores", La Opinión, 5-7-1865, p. 211. La negrita es del autor.

36 "The built environment, like language, has the power to define and refine sensibility. It can sharpen and enlarge consciousness". Yi-Fu Tuan: Space and Place: The Perspective of Experience, Mineápolis, University of Minnesota, 1977, 2014, p. 107.

37 "Los hábitos del aseo revelan además hábitos de orden, de exactitud y de método en los demás actos de la vida". Manuel Carreño: Manual de urbanidad y buenas maneras, México, Editorial Época, [1853], p. 52. Véase igualmente Josefa Acevedo Gómez: Tratado sobre economía doméstica, Bogotá, Imprenta de José A. Cualla, 1848; así como la reflexión sobre lujo, comodidad y aseo en las viviendas bogotanas del siglo XIX, G. Mejía Pavony: Los años del cambio..., pp. 425-427.

${ }^{38}$ Z. Pedraza: En cuerpo y alma..., p. 2.
} 
Basta con adentrarnos en los imaginarios literarios y visuales de la segunda mitad del siglo XIX para entender como la representación de la limpieza escenificó una dinámica de distanciamiento con un mundo natural, tupido, maculado. Un sinnúmero de acuarelas presentó los personajes en espacios limpios o mugrientos, según se representaban notables, citadinos o indígenas y mulatos:

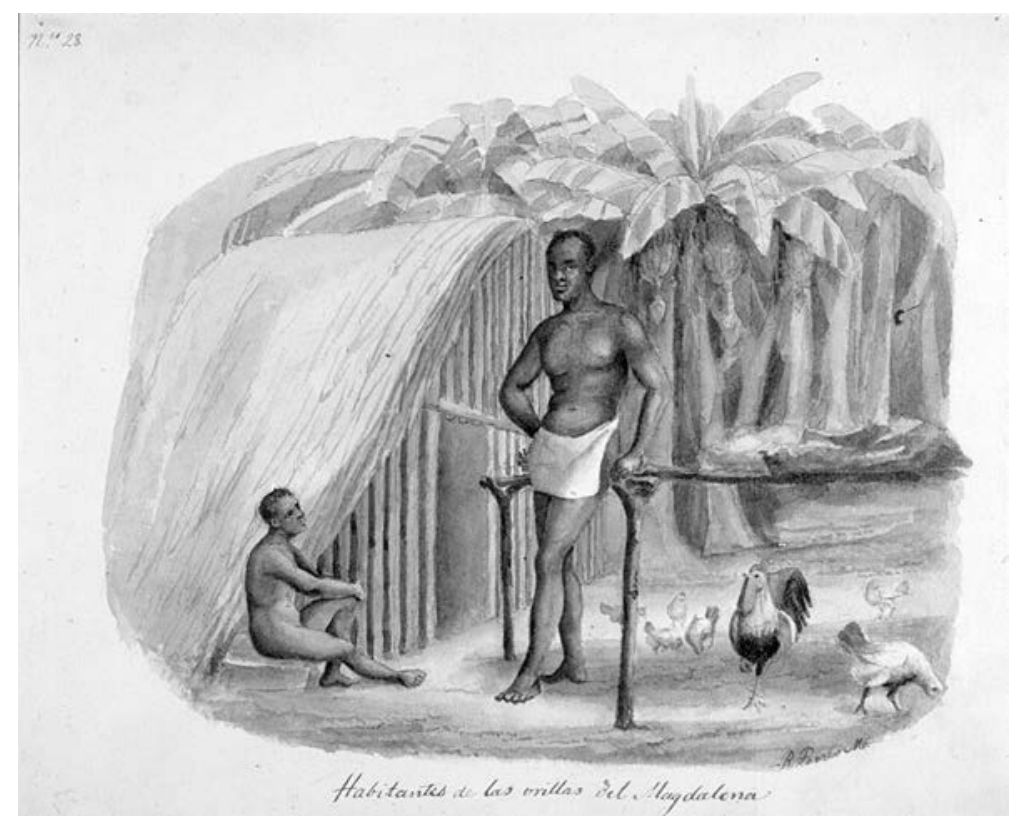

Habitante de las orillas del Magdalena, Ramón Torres Méndez (1850)

El habitante de las orillas del Magdalena, acostado en su hamaca, pasa largas horas del día perezoso y soñoliento [...]. Pero esa vida fácil, abundante, perezosa, enerva sus facultades, lo embrutece y lo degrada. Nace, vegeta, muere y pasa por la vida sin dejar huella ninguna, como los cuadrúpedos en sus bosques ${ }^{39}$. (Emiro Kastos, citado en J. Arias Vanegas: Nación y diferencia..., p. 99).

El espacio limpio, abierto e iluminado fue el escenario privilegiado de los citadinos, de la civilización y la urbanidad.

\footnotetext{
${ }^{39}$ Emiro Kastos, citado en J. Arias Vanegas: Nación y diferencia..., p. 99.
} 


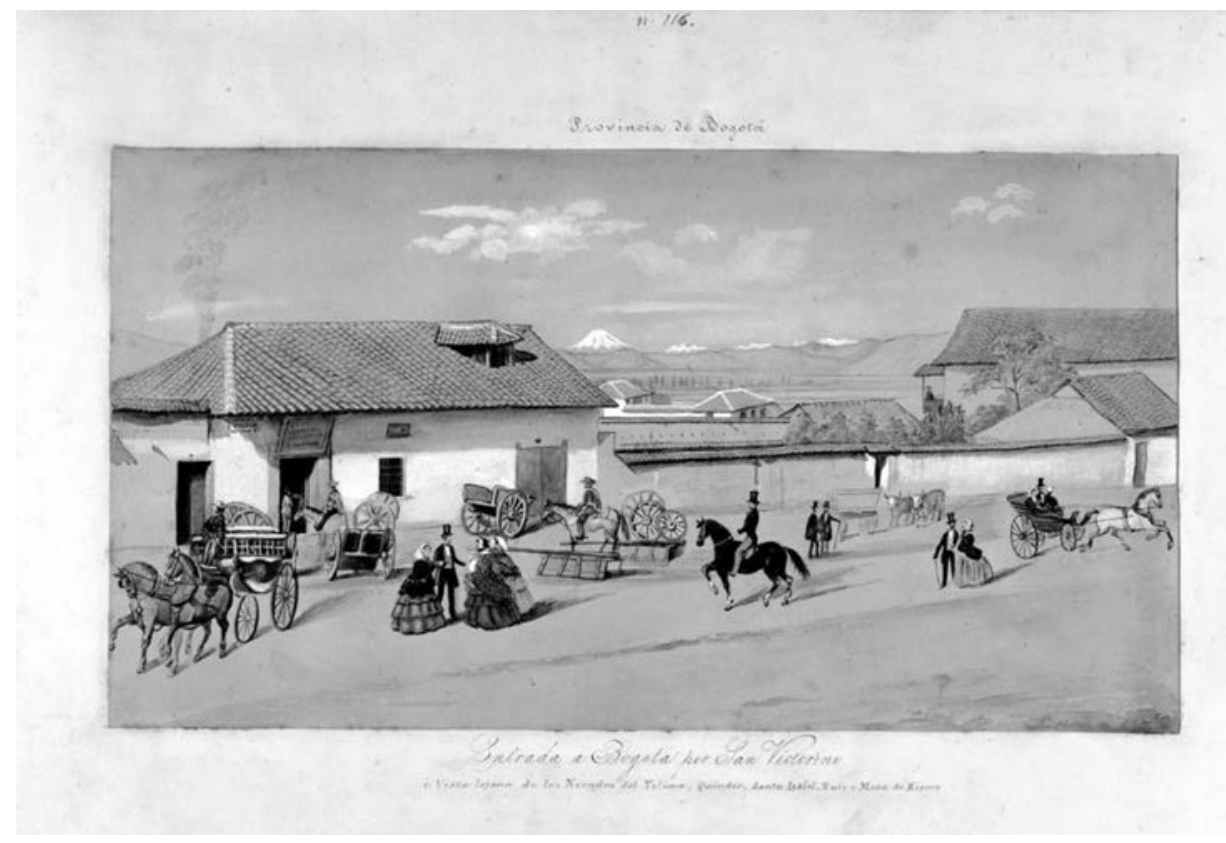

Entrada a Bogotá por San Victorino y vista lejana de los nevados, Manuel María Paz (1857)

En el cuadro aparecen notables de la ciudad, asociados a actividades comerciales y humanas. Los caballeros y las damas se pasean elegantemente, se encuentran y charlan, haciendo de la ciudad un escenario privilegiado de sociabilidad, civilización y urbanidad ${ }^{40}$.

Las mejoras del teatro -nueva silletería, telón de boca, tapetes, techo- aseguraron una mejor calidad del espectáculo: "Si no nos equivocamos, parece que por primera vez en nuestro teatro se ha cantado una ópera al diapasón, sin bajar la orquesta, sin alterar las melodías y sin omitir ni suplir las notas altas en los aires de tenor y barítono" 41 .

Así, mejorar el espacio (más limpio e iluminado) y el sonido (afinado y pulido), resultó en un efecto de sinestesia, en el que la simbología moral y el potencial perfectible del espacio sonoro prepararon un edificio presto a acoger los cuerpos de la élite.

¿Qué tan sensible pudo ser el público a esta experiencia musical? ¿Es suficiente asociar limpieza y vivencia sónica a civilización? Seguro que no.

\footnotetext{
${ }^{40}$ J. Arias Vanegas: Nación y diferencia..., p. 127.
}

41 "Teatro lírico", La Opinión, 15-3-1865, p. 85. 
El nuevo orden "oculocéntrico", teorizado desde una antropología de los sentidos, imperó en la experiencia sensorial de las élites americanas tras la llegada de los europeos $^{42}$. La oralidad, lo olfativo, lo palpable parece haber sido olvidado por una sociedad que privilegió lo escrito sobre lo hablado o lo escuchado ${ }^{43}$. El testimonio de una vivencia multisensorial como lo era la ópera se vio reducido a la superficie plana y llana del relato que se leía, y que es hoy nuestra fuente primaria. El teatro era un lugar en el que el público no solo veía y escuchaba la música: había olores, sensaciones, texturas. El frío, la tos, el olor a cigarrillo, los asientos en mal estados que obligaban a los jóvenes a sentarse "en el borde de una tabla" 44 aparecieron como críticas abiertas a una sociedad que no sabía cómo comportarse. Pero, salvo estos pocos ataques, los cuerpos que iban a la ópera no sonaban, no olían, no se tocaban. Y si sonaban, olían o se tocaban, eran "mal educados", entiéndase la educación como otro grado de distanciamiento de la ignorancia prístina.

Las reseñas presentan pues el teatro como un volumen geométrico aséptico, limpio e iluminado, mudo, que potencia las miradas. A continuación, vamos a analizar la relación entre miradas, actitudes y la regulación de una identidad de élite.

\section{El mirar en el teatro}

Tomen asiento en la orquesta de la Ópera; dirijan sus gemelos no hacia el escenario sino hacia las galerías, al anfiteatro y sobre todo a los palcos principales.

¡Qué cuadros tan variados, cuántas escenas de comedia y, con frecuencia, hasta de drama!

Eugène Scribe: Judit o el palco de la ópera

La mirada del melómano y cronista durante una función del coliseo de Bogotá era una mirada masculina, androcéntrica ${ }^{45}$, que quedó inscrita a través de su pluma. Aquel que describía era un hombre, muchas veces anónimo (o firmaba bajo seudónimo), que ejercía una función simbólica dentro del teatro: vigilar. Sin jerarquía específica, él se encargó de verificar que cada individuo tuviera su lugar en el recinto, según distribuciones concertadas de los cuerpos, con los comportamientos apropiados. Su visión era circular, era global; era panóptica.

\footnotetext{
${ }^{42}$ Constance Classen: "Sweet Colors, Fragrant Songs: Sensory Models of the Andes and the Amazon", American Ethnologist, 17, 4, 1990, pp. 722-735.

${ }^{43}$ Si bien lo escrito es privilegio de una élite, Ana María Ochoa (2014) matiza el poder de lo visual en su estudio sobre los procesos de inscripción de lo sonoro para la construcción de subjetividades en la Colombia del siglo XIX.

44 "Ópera", El Iris, 8-12-1866, p. 317.

${ }^{45}$ Mary Louise Pratt: Imperial Eyes. Travel Writing and Transculturation, Londres, Routlegde, 1992, p. 193.
} 


\section{La mirada del vigía}

Foucault define el panóptico como una "tecnología política”, un sistema arquitectónico y óptico que "garantiza la asimetría, el desequilibrio y la diferencia" ${ }^{46}$. No quisiéramos comparar las engalanadas damas y los elegantes caballeros que asistían a la ópera con los reclusos de una cárcel; sin embargo, algunos aspectos no dejan de tener inesperados puntos de encuentro. Aquel que vigilaba no era un guardia; era un grupo de observadores (que a su vez se observan entre ellos) en el centro del edificio. Quienes eran observado(a)s, pero no observaban a sus observadores, se hacían partícipes de una maquinaria que disoció la pareja ver/ser visto. Apareció entonces otro desequilibrio en el que los dos géneros fueron cómplices, pues en el teatro la mujer era aquella que, al estar "sometida a un campo de visibilidad, y que sabía que lo estaba, reprodujo por su cuenta las coacciones del poder" ${ }^{47}$.

¿Qué se observaba con tanto recelo en el teatro? El sujeto nacional debía ser dueño de un cuerpo disciplinado, como muestra de ese recorrido desde un estado natural, salvaje y vulgar ${ }^{48}$. El cuerpo debía mostrar esas estrategias ("disposiciones, maniobras, tácticas, técnicas y funcionamientos" ${ }^{49}$ ) que, codificadas, incorporadas y estetizadas, constituían la urbanidad. O más bien la disciplina de la urbanidad, una disciplina fisica que atañe lo moral. El ejercicio de la urbanidad (y los manuales que describen sus minucias) normatizan la autocoacción que se espera de los individuos. Anestesiar sus impulsos, contener su sensibilidad, transformar su aparato psíquico por medio de la regulación, el autocontrol o el miedo -en últimas, el control del yo por el superyó- se traduce en códigos visibles (y audibles) que deben persuadir sobre la jerarquía de las personas ${ }^{50}$. La urbanidad no solo fue un termómetro para "medir la civilización"; también fue tal su importancia que se convirtió en el nuevo sistema de clasificación social en las repúblicas americanas ${ }^{51}$.

Observar estos cuerpos adiestrados, entenderlos dentro de una jerarquía de clase (y una distribución espacial decidida por el valor de un boleto), verificar y ratificar su grado de refinamiento fue posible en la ópera por medio de relaciones tensas de miradas. Quisiéramos entonces desenmarañar esta red de miradas para entender, in extremis, si lo visual permitió regular y negociar la identidad civilizada de la élite.

${ }^{46}$ Michel Foucault: Surveiller et punir: naissance de la prison, París, Gallimard, 1975, pp. 203 y 207.

${ }^{47}$ M. Foucault: Surveiller..., p. 204.

${ }^{48}$ Z. Pedraza: En cuerpo y alma..., p. 109.

${ }^{49}$ M. Foucault: Surveiller..., p. 31.

${ }^{50}$ Véase de N. Elias el capítulo "La coacción social y la autocoacción", El proceso de la civilización... así como el libro de Z. Pedraza citado anteriormente.

${ }^{51}$ Z. Pedraza: En cuerpo y alma..., pp. 32, 35 y 50. La autora explica cómo se legitima este nuevo sistema de clasificación republicano sobre la base igualitaria del cristianismo, renunciando a las antiguas clasificaciones coloniales de raza, sangre u origen regional. 


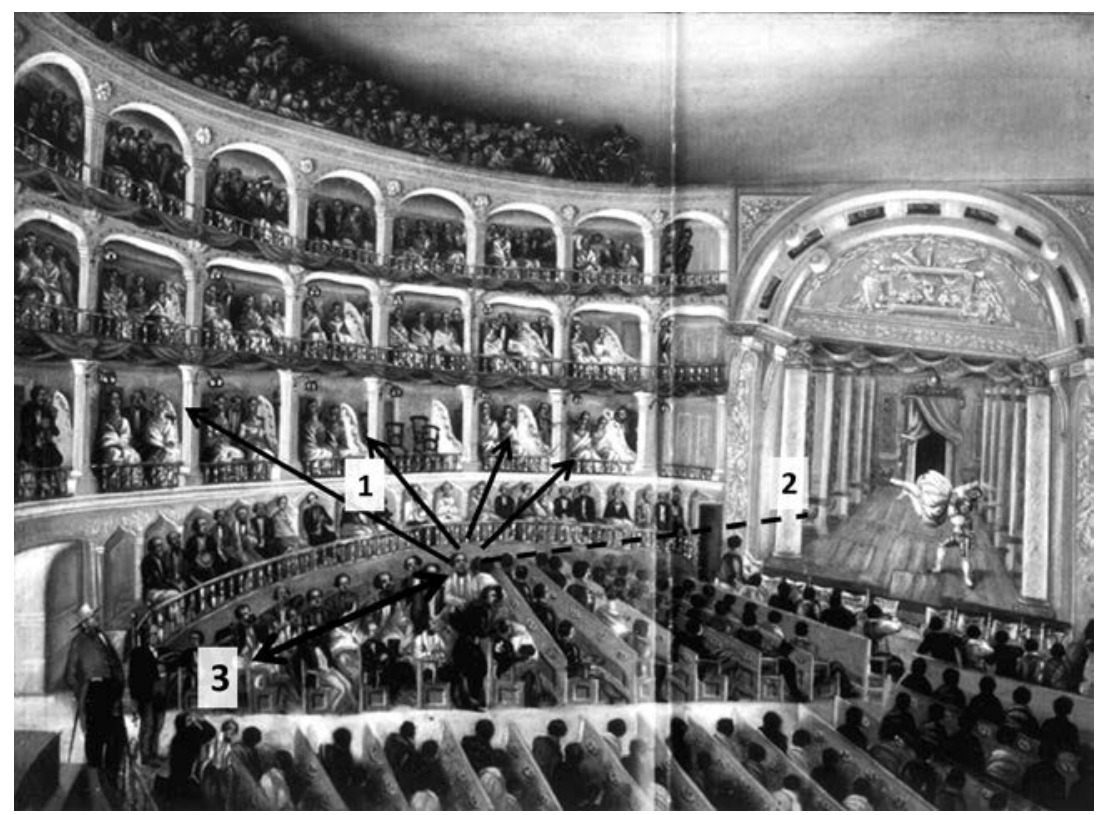

Interior del Teatro San Luís Potosí, Pedro Romero

Al no existir imágenes del interior del Coliseo de Bogotá durante el siglo XIX, usaremos este dibujo del teatro de San Luis Potosí (México) para indicar las miradas del público masculino hacia: 1) los palcos, 2) la escena y 3) entre ellos. Igualmente analizaremos la mirada de los artistas hacia el público, así como la de las señoritas hacia la escena.

Como observadores, estaríamos bien curiosos de saber quiénes estaban en los palcos. Los palcos, alquilados al inicio de cada temporada, funcionaban como extensiones de los hogares de las familias adineradas ${ }^{52}$. La presencia de dignitarios, políticos y reconocidas familias era importante para realzar la función y no faltan las reseñas que enumeran los asistentes a la ópera, como deferencia a su buen gusto.

Por lo general, toda reseña de ópera terminaba con un párrafo sobre la presencia del público femenino:"Profusión de luces, lujo de decoraciones, grandes aparatos escénicos, nada de eso faltó anoche.Y debemos agregar que la belleza femenina tuvo también sus dignas representantes que sirvieron de ornato y complemento a la función" 53 .

\footnotetext{
${ }^{52}$ Luis de Pablo Hammeken: La república de la música. Ópera, politica y sociedad en el México del siglo XIX, México, Bonilla Artigas Editores, 2018, p. 127.

53 "La Traviata", Diario de Cundinamarca, 9-3-1874, p. 426.
} 
Considerada como "el primero de los ornamentos de la nación" comparada a flores y a astros, la mujer consolidaba un decorado, "the woman is landscape" 55 . En algunos teatros latinoamericanos, las mujeres tenían espacios exclusivos reservados para ellas: sillas de la platea del Teatro Tacón de la Habana, la "tertulia" del Colón de Buenos Aires o la "cazuela" del Teatro Solís de Montevideo. Incluso en el Teatro Iturbe de México se dispuso una galería antepuesta a los palcos, exclusivamente para las damas, como un escaparate para exponer la belleza de las

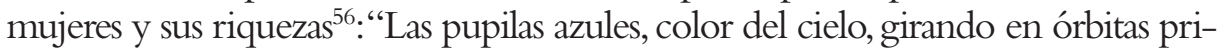
morosas, y los ojos negros esparciendo rayos de amor y esperanza mezclaban su luz y realzaban con ella la lumbre de las lámparas pendientes a trechos en el recinto" 57 .

Estas composiciones estilizadas en las que se convertían los palcos confirman que el deber de las mujeres era gustar a los hombres y permanecer en sus $\operatorname{casas}^{58}$ : la exaltación de su belleza cumplía con el primer propósito; el segundo se hacía al verificar que las mujeres casadas no estuvieran en el teatro: solo sus hijas se exhibían en el palco, considerado como extensión del hogar.

Este decorado femenino, bello y frágil, fue descrito como un jardín. Al final del siglo XIX, cuando se estableció el parque público como nuevo espacio de sociabilidad asociada a la escucha musical de las retretas, las mujeres fueron descritas como el reflejo de las flores del parque... ${ }^{59}$ al menos que la flores reflejaran la grácil feminidad. Esta visión del orden y de la belleza casi taxonómica, en una sociedad inquieta por ordenar las diferentes poblaciones, fue imperativa en el relato fundacional de la élite. El varón era el bárbaro que batallaba en las guerras civiles, incapaz de control y de mesura. Los amoríos y sexualidad desenfrenada de algunos hombres públicos (y no públicos) acallaba toda pretensión del género masculino para presentarse como modelo de morali$\mathrm{dad}^{60}$. En la mujer recayó entonces el incorporar los ideales morales de la burguesía para inculcarlos a su descendencia ${ }^{61}$. Bajo la presión patriarcal y de un mercado matrimonial ${ }^{62}$, la señorita que iba a la ópera debía mostrar esa impecable moralidad a través de conductas apropiadas.

${ }^{54}$ N. Appelbaum: Mapping the Country..., p. 191.

${ }^{55}$ M. L. Pratt: Imperial Eyes..., p. 193.

${ }^{56}$ L. de Pablo Hammeken: La república de la música..., p. 127.

57 "Compañía lírica", Diario de Cundinamarca, 19-1-1874, p. 262.

${ }^{58}$ Susan Rutherford: The Prima Donna and Opera, 1815-1930, Cambridge, Cambridge University Press, 2006, p. 5.

${ }^{59}$ Juan Fernando Velásquez: "From the Plaza to the Parque: Transformations of Urban Public Spaces, Disciplining, and Cultures of Listening and Sound in Colombian Cities (1886-1930)", Latin American Music Review, 38, 2017, pp. 150-184.

${ }^{60}$ Víctor Uribe Urán: "La vida privada de algunos hombres públicos de Colombia: de los orígenes de la República a 1880", Historia de la vida privada en Colombia (1), Jaime Borja, Pablo Rodríguez (eds.), Bogotá, Taurus, 2009, p. 308.

${ }^{61}$ Z. Pedraza: En cuerpo y alma..., pp. 31 y 60.

${ }^{62}$ L. De Pablo Hammeken: La república de la música..., p. 128. 
Por sus contenidos edificantes, la unificación del buen gusto y el retoque de conductas sociales apropiadas en público ${ }^{63}$, la ópera ató a la mujer al porvenir de la patria. Presentarse en público era un examen social al que solo accedían quienes dominaban su cuerpo. De lo contrario, ir al teatro hubiera sido exponerse a la burla pública y al destierro social. El examen, escribe Foucault, "combina las técnicas de la jerarquía que vigila y las de la sanción que normaliza. Es una mirada normalizadora, una vigilancia que permite calificar, clasificar y castigar" ${ }^{\prime 4}$.

\section{La mirada hacia las mujeres: erotismo y nación}

En las ciudades latinoamericanas, subir al proscenio era sinónimo de deshonra para las mujeres locales. Melesio Morales, compositor mexicano, recuerda con amargura la razón por la cual se canceló una función de Il trovatore en 1870:"Se creyeron envilecidas por pisar las tablas y antes de llegar a este extremo prefirieron negarse. Si estas niñas, mejor dicho, si sus familias se imaginaron deshonroso el emplear sus talentos filarmónicos a favor de la niñez, tan solo porque este paso importaba la necesidad de salir a la escena teatral, ¡miseria humana!"65.

En Bogotá, la cantante italiana Marina de Thiolier intentó sin éxito organizar conciertos y temporadas de ópera a partir de $1871^{66}$. Incluso cuando los dueños del coliseo le cedieron gratuitamente el teatro para sus propósitos musicales, "algunas de las señoritas que la secundan, se negaron a cantar en aquel edificio" ${ }^{67}$. Era tal el miedo a la deshonra que los coros de óperas italianas eran interpretados por voces masculinas, cuando no eran cortados. No queda muy claro aún cuáles fueron las temporadas en las que hubo coros mixtos o masculinos. El coro femenino que sí se escuchó, angelical y etéreo, fue el coro tras bambalinas: "El efecto del coro interno de las religiosas 'Ah se l'error t'ingombra' fue maravilloso por su novedad y acorde artístico que sorprendió la espectación [sic.] general de una manera, pudiera decirse, inesperada" 68 .

\footnotetext{
${ }^{63}$ Cuando Rafael Pombo publica el libreto de la ópera colombiana Ester en 1874, insiste en que el tema bíblico de la ópera "debe prevenir en favor de una obra lírica [... ] a los padres de familia que desean para sus hijas espectáculos de perfecta moralidad". Rafael Pombo: "Ester, ópera bíblica en tres actos, Bogotá, imprenta de La América, 1874", José María Ponce de León y la ópera colombiana en el siglo XIX \& Ester, Libreto de Manuel Briceño y Rafael Pombo, Carolina Alzate, Rondy Torres (comps.), Bogotá, Universidad de los Andes, 2014, p. 20.

${ }^{64}$ M. Foucault: Surveiller..., p. 187.

${ }^{65}$ Melesio Morales: Mi libro verde de apuntes e impresiones, Karl Bellinghausen (ed.), México, Memorias Mexicanas, 1999, p. 58.

${ }^{66} \mathrm{R}$. Torres López: "Tras las huellas armoniosas de una compañía lírica: la Rossi-D’Achiardi en Bogotá", Revista del Instituto de Investigación Musicológica Carlos Vega, 26, Buenos Aires, 2012, pp. 161-200.

67 "Hechos diversos", La Igualdad, 7-4-1874.

${ }^{68}$ J. C. Osorio: "Trovador", El Mensajero, 2-1-1867, p. 215.
} 
El coro interno invisibilizó el cuerpo de la mujer, negación relevante en el contexto oculocéntrico que hemos expuesto; la resguardó de una exposición que le arrebataría sus prendas morales frente a la mirada de quienes la veían como futura madre y esposa. El coro tras bambalinas difluía en una plegaria: la cita anterior hace referencia a un coro interno de religiosas del segundo acto de Il trovatore y el efecto "inesperado" inspiró sin duda el "Coro interno" del tercer acto de la ópera colombiana Ester. Poner sus talentos filarmónicos al servicio de evocaciones religiosas y piadosas contribuía a ajustar las prendas morales de estas señoritas, así como su grado de civilización, haciendo "del ser material un ser espiritual, del salvaje un civilizado, del criminal un santo" 69 .

La ópera es representación, y la representación del cuerpo es problemática en las élites latinoamericanas. El cuerpo, su ocultamiento y su relación con el entorno diferenció grupos sociales en la nación en ciernes. Las formas de desnudez, relacionadas con lo bárbaro, fueron rechazadas. En 1880 la compañía lírica Desantis (o de Sanctis) llegó a Bogotá con un conjunto de ballet ${ }^{70}$. Pero las primeras presentaciones provocaron clamores de protestas: las damas se retiran del teatro, la casi-desnudez escandalizó, el ballet fue rechazado: "La empresa de ópera italiana, deseosa de complacer al público, y habiendo oído decir que muchas familias se abstienen de concurrir al teatro porque no les agrade el baile, ha resuelto dar las óperas solas"71.

La inmediata respuesta de El Zipa, diario de corte liberal, nos da un anticipo de lo que pudo ser el debate que se desató en torno a estos tutús:

Finalizó tan bella función con un baile bien ejecutado, al cual se aguardó toda la concurrencia, a pesar del escándalo que habían causado la noche anterior los vestidos de las artistas, vestidos que son indispensables tanto para que pueda distinguirse y admirarse los dificiles pasos y acompasadas figuras que ejecutan, como para dar al espectáculo cierta idealidad que lo hace aparecer como una visión fantástica que nada tiene de terrenal y que por lo mismo no puede ser motivo de escándalo para los que solo vamos a admirar las bellezas del arte $^{72}$.

La mirada sobre la mujer cambiaba radicalmente al tratarse de la prima donna. Su belleza y sacrificio en escena se confundía con el ideal femenino romántico, ya esbozado por Rousseau en la Nueva Eloísa, ya personificado por las heroínas románticas que acompañaron los lectores de la segunda mitad del siglo: Bernardin de Saint-Pierre, Chateaubriand, Byron, Lamartine, Dumas,

\footnotetext{
69 "Los líricos i la ópera de don Pascual", La Opinión, 26-4-1865, p. 135.

${ }^{70}$ Marina Lamus Obregón: Teatro siglo XIX. Compañías nacionales y viajeras, Bogotá, Círculo de lectura alternativa, 2004, p. 399.

71 "Ópera italiana”, La Velada, 5-9-1880 (citado por M. Lamus Obregón: Teatro siglo XIX..., p. 400).

72 "Ópera Italia”, El Zipa, 14-8-1880, p. 37.
} 
Hugo o el Duque de Rivas ${ }^{73}$. La cantante encarnó lo serio de la tragedia; su muerte en escena era el espacio de realización y conocimiento de sí misma ${ }^{74}$ como si el idealismo mágico de Novalis, el plano noúmenal kantiano o la noche-nada de Schopenhauer de repente se representasen en escena:

¿Quién con tu canto celestial, beatífico

no ha sentido su espíritu elevar,

y con tu acento sin igual, magnífico

En un océano de placer estar? ${ }^{75}$

La voz de las artistas europeas, su inalcanzable cuerpo, el enriquecer espiritual y el gozo estético que ellas despertaban fueron alabados públicamente en sonetos. Escritas en prosa, estas alabanzas de sutil erotismo serían inaceptables; versificadas y estilizadas, florecían en la prensa como expresión de máxima galantería ${ }^{76}$.

"A la distinguida artista Señora Josefa Mateo"

lleno de fe con tu virtud fecunda, yo con profunda admiración te vi exhibirte con gracia pudorosa, y amorosa, mi alma la sentí.

Tu airoso talle, tu mirar sencillo, de jilguerillo tu trinada voz, formaron en mi mente tal conjunto que al propio punto me olvidé de Dios. La dulzura que adorna tu sonrisa cual leve brisa inunda al corazón; la ternura que engendran tus acentos, sentimientos me dan de inspiración. Y por eso te miro embelesado y enajenado de oigo de placer: dulce paloma que nació en el Cielo y trajo al suelo un rayo del Edén.

Bogotá, mayo de 1876

Diego Fernando Asencio (Escrito en el Teatro, en la segunda representación de los Madgyares) ${ }^{77}$.

\footnotetext{
${ }^{73}$ R. Torres López: "Introducción", José María Ponce de León..., p. 19.

${ }^{74}$ S. Rutherford: The Prima Donna..., p. 13.

${ }^{75}$ B.M.M.: "A la señora Marina Barbieri de Thiolier", La Paz, 9-2-1869.

${ }^{76}$ Los sonetos que celebraban las cantantes eran frecuentes en Europa. Véase Francesco Izzo: "Divas and Sonnets. Poetry for Female Singers in Teatri arti e letteratura", The Arts of the Prima Donna in the Long Nineteenth Century, Rachel Cowgill, Hilary Poris (eds.), Oxford, Oxford University Press, 2012, pp. 3-20.

${ }^{77}$ D. F. Asencio: "A la distinguida artista", Diario de Cundinamarca, 9-6-1876, p. 723.
} 
¿Por qué aceptar esta práctica que ensalzaba la mujer europea, algo impensable con las mujeres colombianas? ¿El poeta-admirador, "enajenado", cegado por una blasfemadora admiración -"me olvidé de Dios"- respondería acaso al inconsciente eugenésico de blanqueamiento que ya hemos evocado? Un caso concreto, el del tenor italiano Oreste Sindici, nos permite entender esa rápida aceptación de los líricos en familias de la burguesía. Hablaremos esta vez de un hombre puesto que todas las cantantes eran mujeres cuyos esposos participaban en los elencos, ya como empresarios, ya como músicos. Oreste Sindici terminó desposando a una señorita de la élite capitalina. Abandonó su carrera como cantante, puso fin a su vida itinerante para dedicarse a la pedagogía musical y la explotación agrícola ${ }^{78}$. Sindici es la encarnación del europeo que modifica la genética del sujeto nacional, la economía y la cultura de la nación. Pequeño detalle... es el autor del actual himno nacional de Colombia.

\section{La mirada hacia los otros hombres: la mofa}

En la platea, los hombres tenían sus cuarteles. Este era un espacio masculino, olvidado en las reseñas, a menos que fuera necesario señalar ciertos desatinos. Castigat ridendo mores, enmendar las costumbres riendo, no solo era la divisa en los pórticos de algunos corrales de comedias; hubiera podido ser el lema del arte de describir eventos públicos. Pluma en ristre, el cronista señaló vicios o defectos por medio de la sátira y la burla para reformar las costumbres. La falta a la etiqueta se señalaba en anécdotas desengañadas:

De aquí el fiasco solemne e ignominioso que hizo anoche la plebe in-artística (de botas y sombrero de copa alta) que colmaba el teatro así como rellena la paja un cajón de cristalería. [...] Doscientos, por lo menos, aplaudieron con entusiasmo la caída de un farolillo en la escena; más de doscientos desahogaron con palmadas su admiración al ver al bufo, señor Colomé, valsando con la más joven de las coristas; $[\ldots]$ y entretanto la delicadísima, angélica romanza del tenor del primer acto, lo mismo que otros exquisitos números, no merecieron de ella sino el silencio ${ }^{79}$.

La ópera se debía apreciar "por medio de la inteligencia, del sentimiento y del buen gusto" todas estas, facultades que resultaban de una férrea disciplina del cuerpo civilizado; la risa, indecorosa en público, se daba con furor en aquellos espectáculos en donde "cualquier titiritero o maromero viene a mistificarnos con sus cubiletes o barbarizarnos con sus ejercicios de cuadrumano" 80 . Carreño advierte, en su Urbanidad: "Son también actos inciviles y

\footnotetext{
${ }^{78}$ Alexander Klein: Oreste Sindici. Obras completas, Bogotá, Universidad de los Andes, 2017, p. 29.

${ }^{79}$ Florencio [Rafael Pombo]: "El nuevo triunfo de Ponce de León”, El Tradicionista, 2-5-1876, p. 1381

80 "Variedades - Ópera italiana.", La Paz, 29-9-1868.
} 
groseros el conversar o hacer otro ruido en medio del espectáculo [...] reír a carcajadas en los pasajes chistosos de una pieza dramática, prorrumpir en exclamaciones bulliciosas en medio del silencio general y romper en aplausos inoportunos" $"$. Otros ejemplo: "Cuando oigas aplaudir furiosamente algún trozo del gran maestro Barbieri, no imaginéis que lo que admiran es la música; mirad por todos lados y descubriréis que algún actor ha hecho una monada, o algún perro ha invadido la escena. ¡Cosa de ahorcarse, si José María Ponce de León hubiese de escribir para concurrencias solo de títeres y matachines!" 82 .

Estos ejemplos muestran, sin sutileza ni contención, que quien escribía vigilaba. Verificaba el comportamiento del público y señalaba toda aquella disfunción que deslucía el cuerpo civilizado. Se vislumbra también el temor de quien, desde una posición social elevada -en este caso Rafael Pombo-, observa aquellos que tratan de ascender de clase y se convertirían en potenciales competidores ${ }^{83}$.

Salgamos por un momento de la ópera y cambiemos diversión por rezo. En el templo, esperaríamos un ambiente de recogimiento y discreción. Sin embargo:

Hacía apenas algunos momentos que estaba ahí, cuando oí muchas pisadas, y fueron entrando por diferentes partes varias señoritas que llegaron a la iglesia como a un teatro u otra diversión por el estilo; tan engalanadas y compuestas estaban, y con tanta franqueza y desparpajo miraban en torno suyo. Aunque llevaban sayas y mantillas negras como las que acostumbran las señoras de Bogotá para ir al templo, usaban los peinados tan altos y llenos de lazos, cinta, puñales de acero, espadas doradas y demás zarandajas, que están de moda hoy ${ }^{84}$.

Esta cita cumple con un objetivo preciso: la mofa para enmendar las costumbres. Vale señalar que es de los pocos pasajes de la prensa bogotana en donde las mujeres son objeto de burla. Nos ofrece una mirada que contradice las crónicas oficiales de la ópera y sin duda nos invita a matizar la imagen de un grupo de señoritas de impecable conducta. Sobre este tema, volveremos más adelante.

\section{La mirada de los cantantes: Bogotá como sucursal de la civilización}

En este complejo juego de miradas, una última mirada otorgaba un reconocimiento tanto esperado: la de los cantantes europeos hacia el público. Solo ellos, como embajadores de la civilizada Europa, podían dar el crédito que tanto esperaba el público.

\footnotetext{
${ }^{81}$ M. Carreño: Manual de urbanidad..., pp. 144-145.

${ }^{82}$ Florencio [Rafael Pombo]: "El nuevo triunfo...".

${ }^{83}$ N. Elias: El proceso de la civilización..., p. 611.

${ }^{84}$ Renato: "Mis sobrinos en la Iglesia", El Tradicionista, 6-4-1875, p. 1733.
} 
Algunos italianos e italianas decidieron poner fin a su vida nómada y asentarse en Bogotá, como ocurrió con Oreste Sindici. Enrique Rossi-Guerra, cantante, compositor, empresario, corrió con menos suerte y terminó triste y pobremente sus días como jardinero en Bogotá ${ }^{85}$. Algunas cantantes se asentaban algunos años en Bogotá, impartiendo clases de canto y de piano. Escoger Bogotá como residencia era incluir la ciudad dentro de una geografia simbólica de la civilización.

El estreno de las óperas del bogotano Ponce de León por artistas italianos o españoles marcaron momentos cimeros que acreditaron Bogotá como ciudad civilizada $^{86}$. Que la prima donna de una temporada decidiera estrenar una obra nacional para su función de beneficio era causa de gran revuelto y orgullo en la ciudad. Tras el estreno de Ester, los cantantes italianos coronaron al compositor con corona de laureles, gesto simbólico en esta lejana Atenas Americana, evocación a los poetas, deportistas y guerreros griegos ${ }^{87}$.

\section{La mirada de las señoritas: educación y censura}

¿Cuál sería la experiencia de las señoritas en la ópera? Encerradas y con prohibición de escribir públicamente, el tema de la recepción femenina se torna complejo. Su mirada era una mirada controlada y programada de antemano por sus padres que solo las llevaban al teatro si se anunciaban contenidos edificantes, de "perfecta moralidad" 88 . Siendo algunas de ellas conocedoras del lenguaje musical, la ópera les ofrecía la posibilidad de completar su educación musical, así como de experimentar un goce estético que en ningún momento podía traducirse en términos de sensibilidad, a precio de ser criticado como un modismo de mal gusto ${ }^{89}$ :"Las señoritas que se educan en la música no pueden tener una escuela más eficaz que el teatro. Oír con atención una ópera es mucho mejor para ellas que veinticinco lecciones recibidas en la sala de su casa. No dejemos caer la ópera. Es el entretenimiento más noble y más culto que ha ideado la inteligencia humana" 90 .

Sin embargo, la ópera estuvo constantemente entre fuegos cruzados: ¿espectáculo moral o amoral? Mientras que, para algunos, el teatro era una práctica perniciosa, condenada por la iglesia y peligrosa para la salva-

${ }^{85}$ Hay noticias de Rossi-Guerra desde la década de 1830 en México. Su labor como cantante y empresario lo llevó a varios países de América Latina. En Bogotá, además de sus actividades líricas, abrió un restaurante de comida italiana en 1872. R. Torres López: "Tras las armoniosas huellas...", p. 174.

${ }^{86}$ Ester (1874), El castillo misterioso (1876) y Florinda (1880).

${ }^{87}$ R. Torres López: "Ester, relatos de una ópera olvidada", José María Ponce de León..., p. 65.

${ }^{88}$ Rafael Pombo: "Ester, ópera lírica en tres actos, Bogotá, Imprenta de La América, 1874", ibid., p. 20.

${ }^{89}$ En el caso mexicano, la prensa critica las "filarmónicas", es decir, aquellas mujeres que mostraban una excesiva sensibilidad por la música, con el propósito de llamar la atención de los varones. L. de Pablo Hammeken: La república de la música..., p. 120.

90 "El Hebreo", Diario de Cundinamarca, 6-5-1879. 
ción de las almas ${ }^{91}$, otros veían en él el camino hacia la civilización. Y ¡cómo no preocuparse por la juventud con los contenidos de dudosa moralidad en las óperas de Verdi -matricidio, filicidio, fratricidio, prostitución- al tiempo que se ensalzan valores religiosos, nacionales y filiales!92. Para algunos, el simple hecho de ir a la ópera era en sí edificante puesto que evitaba que las personas, en su tiempo de ocio, cayeran en actividades inmorales ${ }^{93}$.

El debate se repetía con cada temporada: "Un respetado sacerdote censuró acremente a las personas que concurrían a los teatros. Esos conceptos despiertan en nosotros tan solo tristeza; por mucho que digamos que estamos en un país civilizado, en donde existe la tolerancia, estamos como ahora veinte años, en el mismo oscurantismo y en el mismo atraso" ${ }^{94}$.

Veinte años atrás, el padre Cera había alzado el puño contra el insigne (y liberal) José María Samper por su drama Dios corrige, no mata ${ }^{95}$. Durante los siguientes años, la anécdota fue evocada con frecuencia, para señalar un clero intolerante y conservador.

En este contexto de contienda ideológica por la ópera, el músico Juan Crisóstomo Osorio publicó seis artículos en la prensa entre diciembre 1866 y marzo 1867, cuya finalidad era instruir e ilustrar al pueblo:

Cuando una compañía de esta clase está dando funciones en una ciudad, los periódicos hacen revistas musicales; pero no es el solo objeto de estas ni el felicitar a los artistas por sus triunfos, ni el enmendar sus defectos, ni el imponer al público del buen o mal desempeño de uno de ellos; las revistas también son, o deben ser, el pretexto de que se vale la prensa para instruir e ilustrar al pueblo ${ }^{96}$.

Las publicaciones periódicas para "el bello sexo" tuvieron una gran importancia en la apreciación de la ópera. Se trata de otro capítulo de la recepción de la ópera en Colombia que queda aún por estudiar. Educar fue,

\footnotetext{
${ }^{91}$ S. Rutherford (The Prima Donna..., p. 38) señala que en Europa existió también una literatura que denigró vehemente la ópera durante el siglo XIX. En el caso colombiano, varias columnas en la prensa condenaron el teatro y la ópera a lo largo del siglo.

${ }_{92}$ Tal podía ser la presión de la censura que fue necesario celebrar el matrimonio entre Margarita y Armando al final de La dama de las Camelias de Dumas (R. Torres López: "Le rêve lyrique en Colombie...", p. 248),

${ }^{93}$ Juan Fernando Velásquez: "Ecos tras bambalinas: el impacto de la actividad de los teatros en la práctica musical, visto a través del caso de Medellín (1886-1903)", Boletín de Música Casa de las Américas, 35, 2013, p. 75. El autor retoma la noción de "ocio edificante" introducida por el filósofo polaco Tatarkiewicz.

94 "Teatro" (R.L.C.), Diario de Cundinamarca, 7-3-1874, p. 424 (la negrita es del autor).

${ }_{95}^{95}$ M. Lamus Obregón: Teatro siglo XIX..., p. 134.

${ }^{96}$ Juan Crisóstomo Osorio: "Revista musical. Ópera", El Mensajero, 27-12-1866, p. 195 (las negritas son del autor). Osorio es también el autor de lo que puede considerarse un texto fundacional para el estudio de la música colombiana, sus "Breves apuntamientos para la historia de la música en Colombia", El Repertorio Colombiano, n. ${ }^{\circ}$ 5, septiembre 1879.
} 
pues, otro de los objetivos de la ópera y de la literatura que surge en torno a esta. Asistir y entender la ópera permitió acrecentar la experiencia civilizadora cuando "el escenario dramático podía irradiar con luz santa". Solo así se cumplía el encargo moral del teatro:"poner en escena la buena pasión premiada, enaltecida, triunfante; y [mostrar] la pasión mala abatida, castigada o sometida a expiación" ${ }^{97}$.

\section{Los límites de la reseña}

A la lectura de lo anterior, el público bogotano parece ejemplar. Esta ejemplaridad nos recuerda, con cierta ironía, un detalle de la historia política del país:Víctor Hugo, al recibir una copia de la constitución de Colombia de 1863, declaró: "Debe ser un país de ángeles", mostrando la brecha entre la realidad del país y su carta magna ${ }^{98}$.Y es que la élite bogotana pareció acomodarse con ese divorcio de la realidad social del país. Aislada entre las montañas, Bogotá resguardó con recelo una prolífica vida literaria y cultural que le valió el nombre de la Atenas Americana por Humboldt, sorprendido por el talento científico y erudito que encontró en los habitantes de la capital del entonces Virreinato de la Nueva-Granada. A lo largo del siglo, los santafereños quisieron mantener su estatuto de cultos y eruditos. Su proverbial buena educación y su afectación cultural alimentó la fábula de una tradición gentil, aún en el siglo $\mathrm{XX}^{99}$.

Mantener a toda costa esta imagen delicada de la capital fue la labor de los cronistas. Además del control ya evocado, estos se impusieron un filtro escritural pues estaban registrando, día a día, el relato oficial de la nación y de sus intachables sujetos.

¿Cómo matizar este relato? La diatriba contra los arreglos de las damas en la iglesia, anteriormente citada, además de provocar una sonrisa, nos da luces sobre los complejos atavíos e impertinencia de las damas en la ópera. Como en muchas partes del mundo, situaciones de flirteo y de seducción debían ocurrir en los palcos ${ }^{100}$. Pero de eso, poca información se tiene.

Así como la burla señaló los defectos, Rafael Pombo escribió este elocuente soneto que nos ofrece una visión diferente de la de las afectadas reseñas:

\footnotetext{
97 "De la moralidad en el teatro", El Conservador, 26 y 31-9-1863.

${ }^{98}$ Jean-Pierre Minaudier: Histoire de la Colombie: de la Conquête à nos jours, París-Montreal, l'Harmattan, Horizons Amériques latines, 1997, p. 151.

${ }^{99}$ Jonathan Brow llamó "tradición gentil" esa afectación en el lenguaje y los comportamientos de los bogotanos ("The Genteel Tradition of Nineteenth Century Colombian Culture", The Americas, 36, pp. 445-464).

${ }^{100}$ S. Rutherford da varios ejemplos en el capítulo "Sirens and Songbirds", The Prima Donna..., p. 39.
} 
Función de teatro ${ }^{101}$

Llovió al entrar, y mucha hermosa dama hecha sopa y con tos al palco llega.

Se alza el telón, y entonces se nos ruega que excusemos un cambio en el programa.

Empieza el Canto. Desde el coro inflama por mofa o chiste al público una lega o lego del país; y no sosiega aunque truenen la música y el drama.

Siempre que el ritmo es llano, algún vecino con su palo o tacón márcalo exacto; y otro va el aria canturreando indino.

Cigarrillo doquier; cada entreacto Enorme... En fin, desértome mohíno y de mi amor al Arte me retracto.

La ruidosa tos, el canto desafinado del coro, el frío y el olor de la ropa mojada, el desorden y la improvisación, el llevar el ritmo o cantar con la música son críticas valiosas, aún más si recordamos que Pombo vivió quince años en Nueva York y que como melómano, fue un asiduo espectador de la Ópera Metropolitana ${ }^{102}$.

\section{Para concluir}

La sociedad del siglo XIX, hija de una época de la vigilancia (el panóptico), es también la sociedad del espectáculo, de las grandes exposiciones, los museos y los conciertos públicos en donde todo se puede observar ${ }^{103}$. Las miradas que se cruzaban durante una función de ópera en el coliseo Bogotá observaban el cuerpo adiestrado, labrado por la disciplina de la urbanidad para vigilar una identidad asociada a lo civilizado. Al umbral del siglo XX, esta vigilancia pasa incluso a ser una actividad policial, como reza la publicación de decretos que confian a la policía la vigilancia del comportamiento del público en los teatros, so pena de cárcel ${ }^{104}$.

\footnotetext{
${ }^{101}$ Rafael Pombo: Poesía inédita y olvidada, tomo I, Bogotá, Instituto Caro y Cuervo, 1970, p. 369.

102 Carolina Alzate: "Rafael Pombo y Ester (1874), ópera colombiana", José María Ponce de León..., pp. 93-107.

${ }^{103}$ Tony Bennett: "The Exhibitionary Complex", Culture/Power/History. A Reader in Contemporary Social Theory, Nicholas Dirks, Geoff Eley, Sherry Ortner (eds.), Princeton, Princeton University Press, 1994, pp. 123-154.

${ }^{104}$ J. F. Velásquez, "Ecos tras bambalinas"..., p. 94, menciona el decreto n. ${ }^{\circ} 83$ del 1-12-1900, transcrito en La Revista Musical de Medellin.
} 
La nación, pensada como un proyecto de diferenciación, más que de unificación ${ }^{105}$, cobijó espacios excluyentes como lo fue la ópera. Las miradas y los comportamientos del público, la materialidad de sus cuerpos y su fuerza simbólica fueron tecnologías políticas al servicio de una "microfisica del poder" Un poder que pretendía definir lo nacional desde lo humano, y no a través de las instituciones o de aparatos estatales. Si consideramos la élite como una subcultura, la definición de lo nacional se convierte entonces en definición de clase, cuya máxima distinción era parecer civilizada. Hoy, confundiríamos civilizado con universal ad-portas del proyecto globalizador del siglo XX.

La reseña atenuó lo incómodo, lo desagradable, lo vulgar y exaltó los comportamientos sofisticados de la modernidad. Fue la vitrina que construyó la memoria de la sociabilidad de la élite. Para los contemporáneos que no podían franquear el filtro monetario de una entrada o que vivían lejos de Bogotá, la reseña era la ventana que permitía asomarse al interior elegante y civilizado del coliseo. Para nosotros, es una de las crónicas que cuentan la historia de la élite. Pero la reseña silenció las voces de las mujeres, así como el de un público modesto que sin duda asistía también a la ópera.

Volver a la experiencia humana como eje de estudio es otro de los nuevos rumbos de las ciencias humanas. La experiencia completa de la ópera -y nuestro análisis tendría su complemento en el estudio de lo sónico, lo táctil, lo emocional, lo estésico- es una distracción que, "al mismo tiempo que ocupa nuestros sentidos, hace nacer en nuestros espíritus ideas gratas" ${ }^{107}$. El cuerpo de la modernidad es un cuerpo que se empieza a percibir como un centro sensible. Es el cuerpo de la dualidad que tiene que equilibrar un sentido de trascendencia -cogito ergo sum- con una nueva materialidad -sentio ergo sum-.

Recibido: 13-9-2018

Aceptado: 11-3-2019

\footnotetext{
${ }^{105}$ J. Arias Vanegas: Nación y diferencia..., p. vii.

${ }^{106}$ M. Foucault: Surveiller..., p. 31.

107 "Variedades - Ópera italiana.", La Paz, 19-2-1869 (el énfasis es del autor).
} 